\title{
Which psychological, social and physical environmental characteristics predict changes in physical activity and sedentary behaviors during early retirement? A longitudinal study.
}

Delfien Van Dyck ${ }^{1,2}$, Greet Cardon ${ }^{2}$, Ilse De Bourdeaudhuij ${ }^{\text {Corresp. } 2}$

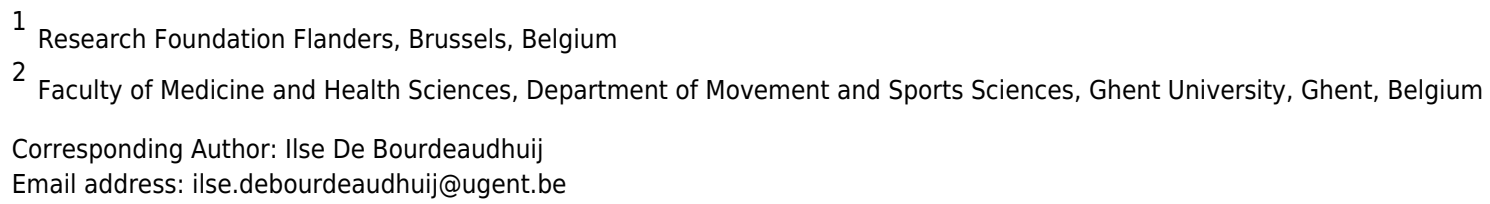

Background: In the context of healthy ageing, it is necessary to identify opportunities to implement health interventions in order to develop an active lifestyle with sufficient physical activity and limited sedentary time in middle-aged and older adults. The transition to retirement is such an opportunity, as individuals tend to establish new routines at the start of retirement. Before health interventions can be developed, the psychological, social and physical environmental determinants of physical activity and sedentary behaviors during early retirement should be identified, ideally with longitudinal studies. The aim of this paper was first to examine whether psychological, social and physical environmental factors at the start of retirement predict longitudinal changes in physical activity and sedentary behaviors during the first years of retirement. Second, moderating effects of gender and educational levels were examined. Methods: This longitudinal study was conducted in Flanders, Belgium. In total, 180 recently retired ( $>1$ month, $<2$ years at baseline) adults completed a postal questionnaire twice (in 2012-2013 and two years later in 2014-2015). The validated questionnaire assessed socio-demographic information, physical activity, sedentary behaviors, and psychological, social and physical environmental characteristics. Multiple moderated hierarchic regression analyses were conducted in SPSS 22.0. Results: Higher perceived residential density $(p<0.001)$ and lower aesthetics $(p=0.08)$ predicted an increase in active transportation (adjusted $R^{2}=0.18$ ). Higher baseline self-efficacy was associated with an increase in leisure-time physical activity ( $p=0.001$, adjusted $\left.R^{2}=0.13\right)$. A more positive perception of old age $(p=0.04)$ and perceiving less street connectivity $(p=0.001)$ were associated with an increase in screen time (adjusted $\left.R^{2}=0.06\right)$. Finally, higher baseline levels of modeling from friends $(p=0.06)$ and lower perceived land use mix access $(p=0.09)$ predicted an increase in car use (adjusted $\mathrm{R}^{2}=0.06$ ). A few moderating effects, mainly of educational level, were found. 
Discussion: Walkability characteristics (perceived residential density) and self-efficacy at the start of retirement are the most important predictors of longitudinal changes in active transportation and leisure-time physical activity. Few moderating effects were found, so health interventions at the start of retirement focusing on self-efficacy and specific walkability characteristics could be effective to increase physical activity in recently retired adults. No firm conclusions can be drawn on the importance of the examined predictors to explain change in car use and screen time, possibly other factors like the home environment, or automatic processes and habit strength are more important to explain sedentary behaviors. 
1 Which psychological, social and physical environmental characteristics predict changes in

2 physical activity and sedentary behaviors during early retirement? A longitudinal study.

3 Delfien Van Dyck ${ }^{1,2}$, Greet Cardon ${ }^{2}$, Ilse De Bourdeaudhuij ${ }^{2}$

4

$5 \quad{ }^{1}$ Research Foundation Flanders, Brussels, Belgium

$6{ }^{2}$ Ghent University, Faculty of Medicine and Health Sciences, Department of Movement and

7 Sports Sciences, Ghent, Belgium

8

9 Corresponding author

10 Ilse De Bourdeaudhuij

11 Ghent University, Faculty of Medicine and Health Sciences

12 Department of Movement and Sports Sciences

13 Watersportlaan 2, 9000 Ghent, Belgium

14003292646311

15 Ilse.debourdeaudhuij@ugent.be

\section{Abstract}

Background: In the context of healthy ageing, it is necessary to identify opportunities to

21 implement health interventions in order to develop an active lifestyle with sufficient physical

22 activity and limited sedentary time in middle-aged and older adults. The transition to retirement

23 is such an opportunity, as individuals tend to establish new routines at the start of retirement. 
24 Before health interventions can be developed, the psychological, social and physical

25

environmental determinants of physical activity and sedentary behaviors during early retirement

should be identified, ideally with longitudinal studies. The aim of this paper was first to examine whether psychological, social and physical environmental factors at the start of retirement predict longitudinal changes in physical activity and sedentary behaviors during the first years of retirement. Second, moderating effects of gender and educational levels were examined.

Methods: This longitudinal study was conducted in Flanders, Belgium. In total, 180 recently retired ( $>1$ month, $<2$ years at baseline) adults completed a postal questionnaire twice (in 20122013 and two years later in 2014-2015). The validated questionnaire assessed socio-demographic information, physical activity, sedentary behaviors, and psychological, social and physical environmental characteristics. Multiple moderated hierarchic regression analyses were conducted in SPSS 22.0.

Results: Higher perceived residential density $(\mathrm{p}<0.001)$ and lower aesthetics $(\mathrm{p}=0.08)$ predicted an increase in active transportation (adjusted $\mathrm{R}^{2}=0.18$ ). Higher baseline self-efficacy was associated with an increase in leisure-time physical activity ( $\mathrm{p}=0.001$, adjusted $\mathrm{R}^{2}=0.13$ ). A more positive perception of old age $(p=0.04)$ and perceiving less street connectivity $(p=0.001)$ were associated with an increase in screen time (adjusted $\mathrm{R}^{2}=0.06$ ). Finally, higher baseline levels of modeling from friends $(p=0.06)$ and lower perceived land use mix access $(p=0.09)$ predicted an increase in car use (adjusted $\mathrm{R}^{2}=0.06$ ). A few moderating effects, mainly of educational level, were found.

Discussion: Walkability characteristics (perceived residential density) and self-efficacy at the start of retirement are the most important predictors of longitudinal changes in active transportation and leisure-time physical activity. Few moderating effects were found, so health 
47 interventions at the start of retirement focusing on self-efficacy and specific walkability

48 characteristics could be effective to increase physical activity in recently retired adults. No firm

49

50

51

52

53

54

55

56

57

58

59

60

61

62

63

64

65

66

67

68

69 conclusions can be drawn on the importance of the examined predictors to explain change in car use and screen time, possibly other factors like the home environment, or automatic processes and habit strength are more important to explain sedentary behaviors.

\section{Introduction}

Globally, life expectancy has increased steadily over the last decades. Between 2000 and 2050, the proportion of adults older than 60 years of age is expected to double from $11 \%$ to $22 \%$ (i.e. from about 605 million to more than a billion) (World Health Organization, 2014). This trend induces major societal challenges, like an increase in health care costs due to age-related chronic diseases (e.g. cardio-vascular diseases, type 2 diabetes, sarcopenia) (Organization for Economic Cooperation and Development, 2006). In middle and older age adopting and adhering to a healthy lifestyle with sufficient levels of physical activity (PA), limited sedentary time and a healthy diet, is needed to reduce risks for chronic diseases and mortality (Knoops et al, 2004; King, Mainous \& Geesey, 2007). In that context, it is necessary to identify opportunities to develop healthy lifestyles in middle-aged and older adults in order to promote healthy ageing.

The transition to retirement can be seen as such an opportunity. Retirement can be defined as 'a permanent and complete withdrawal from the labor force' and goes together with important changes in time availability and flexibility, social networks, income and financial security, which can all impact adults' lifestyles, both positively and negatively (Kim \& Moen, 2002; Barnett, 
70

71

72

73

74

75

76

77

78

79

80

81

82

83

84

85

86

87

88

89

90

91

92

Van Sluijs \& Ogilvie, 2012). Currently available evidence shows that PA and sedentary

behaviors rather develop adversely during early retirement: total PA tends to decrease when

making the transition to retirement, and this decrease is probably caused by a decrease in work-

and transport-related PA that is insufficiently compensated by an increase in leisure-time PA

(Slingerland et al, 2007; Touvier et al, 2010; Lahti et al, 2011; Barnett et al, 2014). Retirement

has also been associated with an increase in specific sedentary behaviors like TV viewing and reading, and a decrease in occupational sitting and car use (Touvier et al, 2010; Barnett et al, 2014; Sprod et al, 2015; Van Dyck et al, in press).

Nonetheless, retirement can also be seen as a transition during which individuals rethink habitual behaviors and establish new routines (Jonsson, Josephsson \& Kielhofner, 2001). Individuals who are about to retire or retired recently seem to be particularly receptive to behavior change (e.g. smoking cessation) (Lang et al, 2007). So, early retirement seems to be a promising stage to implement interventions to stimulate middle-aged and older adults to develop/maintain a healthy lifestyle.

Before one can develop interventions aiming to increase PA and/or decrease sedentary behaviors during early retirement, it is necessary to identify the specific psychological, social and physical environmental determinants of these behaviors during early retirement. In health research, socioecological frameworks are often used the examine the multi-dimensional determinants of PA (Sallis et al, 2008). The socio-ecological framework for PA has been adapted to examine the potential determinants of sedentary behaviors, but empirical evidence on these determinants is lacking, especially in older adults (Owen et al, 2011). A few qualitative studies examined these 
93 determinants during early retirement, mainly by conducting focus group interviews with the

94 target group (Barnett, Guell \& Ogilvie, 2012; McDonald et al, 2015; Kosteli, Williams \&

95 Cumming, 2016; Van Dyck et al, in press). These studies identified that several intrapersonal

96 (e.g. self-efficacy, self-regulatory strategies, outcome expectations, social norms and beliefs on

97 ageing and retirement, need for personal challenges, perceived health benefits of PA, financial

98 constraints, loss of daily structure), interpersonal (e.g. social support, social roles and

99 responsibilities) and physical environmental factors (e.g. opportunities to be active, physical

100 barriers like poorly maintained sidewalks) can be important factors for (insufficient) PA in

101 recently retired adults. To our knowledge, only one qualitative study already examined potential

102 determinants of sedentary behaviors during early retirement (Van Dyck et al, in press) and

103 concluded that in this age group knowledge on the negative effects of sedentary behaviors is

104 absent, inducing a lack of motivation to decrease sedentary behaviors.

106 In addition to the qualitative evidence, quantitative studies are also needed to confirm the

107 importance of the determinants that emerged from previous focus group studies. Although

108 qualitative studies are very useful, they usually include small study samples. Consequently,

109 quantitative studies with larger samples are more appropriate to draw conclusions for 'the overall

110 population'. To our knowledge, no previous quantitative studies examined the multidimensional

111 correlates of PA and sedentary behaviors in this specific target group of recently retired adults.

112 Ideally, such studies should use a longitudinal design in order to draw conclusions on whether

113 specific factors at the start of retirement predict changes in PA and sedentary behaviors during

114 early retirement, and to make it possible to develop effective health interventions focusing on

115 specific determinants at the start of retirement. 
117 Therefore, the first aim of this paper was to examine whether psychological, social and physical

118 environmental factors at the start of retirement predict longitudinal changes in leisure-time PA,

119 active transportation, screen time and car use during the first years of retirement. Because

120 changes in PA and sedentary behaviors during early retirement have been shown to be dependent

121 of gender and variations in socio-economic status (Mein et al, 2005; Chung et al, 2009; Barnett,

122 Van Sluijs \& Ogilvie 2012; Barnett et al, 2014), the second aim was to examine whether gender

123 and educational level moderate the associations examined in the first aim.

124

\section{Materials and methods}

126

127 This study was conducted in Ghent (250,000 inhabitants, 156.18 square km (60.3 square miles),

1281601 inhabitants/square km), Flanders, Belgium. Baseline data were collected in two waves, a

129 first wave in December 2012 and a second wave in May 2013. Follow-up data were similarly

130 collected in two waves, two years after baseline data collection (December 2014, May 2015).

131

132

Procedures and participants

133

134 The data used for this paper were part of a larger study in adults around retirement age where at

135 baseline, individuals who retired recently ( $>1$ month, $<5$ years of retirement) and individuals

136 who planned to retire within the next 18 months were targeted. However, because this paper

137 aims to examine whether psychological, social and physical environmental factors assessed at

138 the beginning of retirement, can predict changes in PA and sedentary behaviors during early 
139 retirement, only the data of individuals who are at the start of their retirement $(>1$ month, $<2$

140 years of retirement) are used. This definition of 'early retirement' was chosen after consulting

141 sessions with experts in health research in older adults and after four focus group sessions with

142 retired adults. These focus groups were conducted in the scope of another study in the same

143 target group (Van Dyck et al, in press). More details on the procedures of the larger study and the

144 selection of the analytical sample for the current paper, can be found below.

146 In Flanders, the formal retirement age of the current workforce over 50 years of age lies between

14758 and 65 years (http://www.onprvp.fgov.be), but official records with information on retirement

148 status are not publicly available. Consequently, the Public Service of Ghent selected a random

149 sample of $750058-65$ year old adults from the municipal register for the study. At baseline, all

150 these adults received an invitation letter with information on the study (2500 adults in December

1512012,5000 adults in May 2013). Only adults who planned to retire within the next 18 months,

152 and those who had been retired for more than one month but less than five years could

153 participate in the large-scale study. Retired adults needed to be fully retired from their main

154 occupation, but engaging in voluntary work was allowed. Furthermore, as PA was one of the

155 outcome variables, participants had to be able to walk 100 meters without assistance in order to

156 be eligible. Adults who were willing to participate in the study and met the inclusion criteria,

157 received a postal questionnaire (with a pre-stamped envelope to return the questionnaire)

158 including questions on socio-demographic characteristics, psychological, social and physical

159 environmental factors, PA and sedentary behaviors, and physical and mental health. In total, 597

160 adults (455 retired, 142 planning to retire) returned a complete questionnaire. Because it is 
161 unknown how many of the 7500 addressed adults were eligible to participate in the study, it is 162 not possible to calculate the response rate.

163

164 After two years (December 2014 and May 2015) these 597 adults received the same postal 165 questionnaire again (follow-up measurements). In total, 463 adults (77.6\%) returned a complete 166 questionnaire at follow-up. Of these 463 participants, five were not yet retired, three did not 167 report the month/year of retirement, and 9 participants had not been working before they 168 officially retired (seven housewives and two disabled persons). Consequently, the final sample 169 that completed both baseline and follow-up measurements of the large-scale study consisted of 170446 participants (341 adults who were already retired at baseline and 105 adults who retired 171 between baseline and follow-up). For this paper, the 105 adults who were not retired yet at 172 baseline and adults who had been retired for more than two years at baseline $(n=161)$ were 173 excluded from the analyses. This led to a final analytical sample of 180 adults who were at the 174 start of retirement at baseline.

176 The study protocol was approved by the ethics committee of the Ghent University Hospital 177 (B670201215326). Written informed consent was obtained from all participants.

Measures

Dependent variables: Changes in physical activities and sedentary behaviors

182 Self-reported PA was assessed with the International Physical Activity Questionnaire (IPAQ;

183 long past seven days version; available at http://www.ipaq.ki.se). PA assessed by the IPAQ 
184 showed good reliability (intra-class correlations range from 0.46 to 0.96 ) and fair-to-moderate

185 criterion validity compared against accelerometers (median $\rho=0.30$ ) in a 12-country study (Craig

186 et al, 2003). Frequency (number of days) and duration (minutes/day) of PA in different domains

187 were queried. Based on this information, separate estimates of weekly minutes of active

188 transportation (sum of walking and cycling for transport) and leisure-time PA (sum of leisure-

189 time walking, cycling and moderate-to-vigorous PA (MVPA)) were calculated.

190

191 Self-reported minutes/week of car use and screen time (sum of TV viewing time and computer

192 use) were assessed using a translated (Flemish) version of the leisure-time sedentary behavior

193 questionnaire developed by Salmon and colleagues (2003). The English-language version of the

194 questionnaire has fair to excellent reliability (intra-class range from 0.56 to 0.82 ). Concurrent

195 validity, assessed against a three-day behavioral log was fair-to-moderate, with rho's ranging

196 from 0.20 to 0.60 (Salmon et al, 2003).

197

198 Predictors: Psychological, social and physical environmental characteristics

199

200

All psychological variables assessed in the questionnaire were derived from previous studies in

201

adults, older adults and adolescents (Marcus et al, 1992; De Bourdeaudhuij \& Sallis, 2002;

202

Deforche et al, 2004; De Bourdeaudhuij et al, 2005; Van Holle et al, 2015; English Longitudinal

203

Study of Ageing, available at http://elsa-project.ac.uk). Five categories of psychological

204

variables were included: perceived benefits of PA, perceived barriers towards PA, self-efficacy,

205

perceptions of retirement and perceptions of old age. Scales were constructed for perceived

206

benefits of PA (e.g. losing weight, enjoyment; mean of six items, Cronbach's alpha $(\alpha)=0.56$ ), 
207 perceived barriers (e.g. feeling to old, fear for injuries, bad weather; mean of 11 items, $\alpha=0.87$ ),

208 self-efficacy (e.g. being active even when not feeling well, being active even without a sport

209 partner; mean of five items, $\alpha=0.82$ ) and perceptions of old age (e.g. old age is accompanied by

210 loneliness, we can learn a lot from old people; mean of 11 items, $\alpha=0.65)$. Perceptions of

211 retirement consisted of two items that were analyzed separately: 'I perceive retirement as a start

212 for slowing down' and 'I perceive retirement as a start for a more active lifestyle'. All items were

213 scored on a five-point scale with a higher score reflecting more positive psychological profiles,

214 except for the self-efficacy items, which were scored on a three-point scale (I know I cannot, I

215 think I can, I know I can).

216

217 Social variables included modelling, social support and social cohesion of the neighborhood. All 218 variables were derived from previous studies in adults (Sallis et al, 1987; Sampson, Raudenbush

219 \& Earls, 1997; De Bourdeaudhuij \& Sallis, 2002). Modelling consisted of three items (modelling

220 from partner, friends, (grand)children) that were assessed using a seven-point scale (higher score

$221=$ more perceived modelling). These items were analyzed separately due to low internal

222 consistency $(\alpha<0.50)$. Scales were constructed for social support (e.g. how often do friends

223 support you to be active; six items, $\alpha=0.85$ ) and social cohesion of the neighborhood (e.g. people

224 in my neighborhood can be trusted, this is a close-knit neighborhood; five items, $\alpha=0.82$ ). These

225 items were scored on a five-point scale ranging from strongly disagree to strongly agree (higher

226 score $=$ more positive social characteristics).

227

228 To assess perceived physical environmental factors, the Dutch version of the NEWS

229 questionnaire was used (De Bourdeaudhuij, Sallis \& Saelens, 2003). Physical environmental 
230 subscales included were residential density, land use mix diversity, land use mix access, street

231 network connectivity, infrastructure and safety for walking and cycling, traffic safety, crime

232 safety and aesthetics. Land use mix diversity can be defined as 'the level of integration of

233 different types of uses for physical space within an area, including residential, office,

234 retail/commercial, institutional, industry and public space' (Saelens et al, 2003). Land use mix

235 access refers to the accessibility (e.g. distance and presence/absence of physical barriers) of

236 destinations. Street network connectivity can be defined as 'the directness or ease to travel

237 between two points that is directly related to the characteristics of street design' (e.g. many

238 intersections, few dead-end-streets) (Saelens et al, 2003). Calculation of these subscales was

239 based on the official NEWS scoring guidelines (available at http://sallis.ucsd.edu), with a higher

240 score reflecting a more positive environmental perception. The Dutch NEWS has acceptable to

241 good reliability (intraclass correlation coefficients between 0.40 and 0.97 ) and acceptable

242 validity (coefficients between 0.21 and 0.91) (De Bourdeaudhuij, Sallis \& Saelens, 2003). All

243 environmental factors were rated on a four-point scale, except for residential density (three-point

244 scale) and land use mix diversity (five-point scale).

246 Socio-demographic covariates and moderators

247 Self-reported socio-demographics included gender, age, weight, height and educational level

248 (primary, secondary, tertiary education). BMI was calculated by dividing the weight (kg) by the

249 height (m) squared. For the analyses, educational level was dichotomized into high education

250 (i.e. tertiary education) versus low education (i.e. primary and secondary education).

251

252 Statistical analyses 
254 All data were analyzed using SPSS 22.0 and multiple moderated hierarchic regression analyses

255 were conducted to answer the research questions. In a first step, measures of change in PA

256 (active transportation and leisure-time PA) and sedentary behaviors (screen time and car use)

257 between baseline and follow-up were created by regressing the PA and sedentary behavior

258 measures at follow-up onto their respective baseline values. Based on these regression outcomes,

259 residualized change scores were computed. These scores can be interpreted as the amount of

260 increase/decrease in PA or sedentary time between baseline and follow-up, independent of

261 baseline scores. Furthermore, they eliminate autocorrelated error and regression to the mean

262 effects and are therefore preferable to simple change scores (Cohen \& Cohen, 1985; Bland \&

263 Altman, 1994).

264

265

In a second step, multicollinearity $(r>0.60)$ between the predictors (psychological, social and physical environmental characteristics) was analyzed. Only between perceived land use mix

267 access and land use mix diversity $(\mathrm{r}=0.65)$ and between self-efficacy and perceived barriers towards PA $(r=0.62)$ multicollinearity was present. Consequently, only the predictor with the strongest correlation with the dependent variable was included in the regression analyses. In a third step, bivariate correlations between the potential predictors and the outcome variables were examined. Only predictors that had a correlation with the dependent variable of $p<0.15$ were included in the regression models (Tabachnik \& Fidell, 2007).

In a final step, multiple moderated hierarchic regression analyses were conducted to examine whether psychological, social and physical environmental factors at the start of retirement 
276 predicted changes in PA and sedentary behaviors during early retirement, and the moderating

277 effects of gender and educational level. Eight regression models were constructed, two for each

278 dependent variable (residualized change scores of active transportation, leisure-time PA, screen

279 time and car use). In a first block, the socio-demographic covariates (gender, age, BMI,

280 educational level) were entered. In a second block, the psychological, social and physical

281 environmental factors (predictors; baseline values) were entered as independent variables. In the

282 third block, the cross-products (gender $\times$ predictor or educational level $\times$ predictor) were added

283 to examine the moderating effects of gender (four models, one for each dependent variable) and

284 educational level (four models). In case of significance, separate regression models (men versus

285 women or high versus low educational level) were run to interpret the direction of the

286 interaction. Statistical significance was set at 0.05 but because of the small study sample,

287 marginally significant results $(\mathrm{p}<0.10)$ were also reported. In physical activity research it is

288 common to report on marginally significant findings when the sample size is limited (e.g. Van

289 Holle et al, 2016; De Cocker et al, 2016).

290

291 Results

292

293 Baseline descriptive statistics of the study sample are presented in Table 1. In summary, 48.6\%

294 of the sample was male, mean age was 62.5 (2.1) years, $45.5 \%$ of the sample had a low

295 educational level (i.e. no college or university degree) and mean BMI was 25.4 (3.9) $\mathrm{kg} / \mathrm{m}^{2}$.

296 Average values of the psychological, social and physical environmental factors, and of the

297 outcome variables (PA and sedentary behaviors) can also be found in Table 1. 
299 For change in active transportation, the following nine predictors were included in the regression

300 model: self-efficacy, perceiving retirement as a start for slowing down, modelling from

301 (grand)children, neighborhood social cohesion, residential density, land use mix access, street

302 connectivity, infrastructure/safety for walking and cycling and aesthetics. Six predictors were

303 included in the model for change in leisure-time PA: perceived benefits, self-efficacy, perceiving

304 retirement as a start for being active, modelling from partner, land use mix access and traffic

305 safety. Perception of old age and street connectivity were included as predictors in the model for

306 change in screen time. Finally, modelling from friends, residential density and land use mix

307 access were included in the model for change in car use.

308

309

310

Insert Table 1 near here

311

312

313

314

effects of gender and educational level

315

316

Results of the regression analyses are presented in Table 2 . Perceived residential density

$317(\beta=0.41, \mathrm{p}<0.001)$ and perceived aesthetics $(\beta=-0.18, \mathrm{p}=0.08)$ were (marginally) significant

318 predictors of changes in active transportation (adjusted $\mathrm{R}^{2}=0.179$ ). Higher perceived residential

319 density and lower perceived aesthetics at baseline were related to an increase in active

320

transportation. Educational level moderated the relation between modelling from (grand)children

321

and change in active transportation $(\beta=0.66, p=0.09)$. In participants with a low educational 
322 level, no association was found between modelling from (grand) children and change in active

323 transportation $(\beta=0.06, \mathrm{p}=0.68)$ whereas in participants with a high educational level, higher

324 modelling from (grand)children was related to an increase in active transportation $(\beta=0.22$,

$325 \mathrm{p}=0.06$ ). No other moderating effects, neither of educational level, nor of gender could be

326 identified with regard to change in active transportation.

327

328 Regarding change in leisure-time PA, baseline self-efficacy was the only significant predictor $(\beta$ $329=0.32, \mathrm{p}=0.001$; adjusted $\left.\mathrm{R}^{2}=0.134\right)$. Higher baseline levels of self-efficacy were associated with 330 an increase in leisure-time PA. Educational level moderated the relation between perception of 331 retirement (i.e. retirement is a start for a more active lifestyle) and change in leisure-time PA $332(\beta=-0.67, p=0.045)$. In participants with a low educational level, a more positive perception of 333 retirement was related to an increase in leisure-time PA $(\beta=0.35, p=0.002)$ while in participants 334 with a high educational level, no association was found $(\beta=0.06, p=0.56)$. No other moderating 335 effects of educational level or gender could be identified.

Insert Table 2 near here 
344 Results of the regression analyses are presented in Table 3. Baseline perception of old age $345(\beta=0.16, p=0.04)$ and perceived street connectivity $(\beta=-0.25, p=0.001)$ were significantly related 346 to change in screen time (adjusted $\mathrm{R}^{2}=0.064$ ). A more positive perception of old age and

347 perceiving less street connectivity were associated with an increase in screen time. Educational 348 level and gender were not significant moderators of any of the associations.

350 Regarding change in car use, baseline modeling from friends $(\beta=0.21, p=0.06)$ and perceived

351 land use mix access $(\beta=-0.20, p=0.09)$ were (marginally) significant predictors (adjusted $352 \mathrm{R}^{2}=0.058$ ). Higher baseline levels of modeling from friends and lower perceived land use mix 353 access were associated with an increase in car use. Educational level and gender were marginally 354 significant moderators of the relation between modelling from friends and change in car use $355(\beta=0.63, p=0.06$ and $\beta=-0.54, p=0.08)$. In females $(\beta=-0.01, p=0.94)$ and participants with a low 356 educational level $(\beta=0.04, p=0.83)$ no relation could be identified. In males $(\beta=0.23, p=0.10)$ 357 and participants with a high educational level $(\beta=0.24, p=0.07)$, higher baseline levels of modelling from friends were marginally significantly associated with an increase in car use. No other moderating effects were found. 
367 To our knowledge, this was the first quantitative study with a longitudinal design examining the

368 multidimensional correlates of PA and sedentary behavior in recently retired adults. This paper

369 aimed to examine whether psychological, social and physical environmental factors at the start of

370 retirement can predict longitudinal changes in leisure-time PA, active transportation, screen time

371 and car use during the first years of retirement. Furthermore, potential moderating effects of

372 gender and educational level were examined.

373

374 Overall, the results showed that only a limited number of the included factors were associated

375 with changes in PA and sedentary behaviors. Some moderating effects, mainly of educational

376 level, were found, suggesting that to a certain extent, distinct approaches could be preferable to

377 optimally reach high- and low-educated individuals in future interventions. However, as most of

378 these moderating effects of educational level were only marginally significant, no definite

379 conclusions can be drawn. Future studies with larger study samples are needed to examine this

380 more thoroughly. Furthermore, the explained variance of the correlates was considerably larger

381 for changes in PA (13.4\% for change in leisure-time PA and 17.9\% for change in active

382 transportation) than for changes in sedentary behaviors (5.8\% for change in car use and $6.4 \%$ for

383 change in screen time). This could be due to the fact that the content of the questions to assess

384 the psychological, social and physical environmental factors primarily focused on PA and not

385 specifically on sedentary behaviors; for instance, modelling was assessed by asking how often

386 the participants' partner/friends/(grand)children were physically active, and perceived

387 barriers/benefits were queried towards PA. Only the questions about participants' perceptions of

388 retirement, perceptions of old age, social cohesion of the neighborhood and specific physical

389 environmental factors (e.g. residential density, aesthetics) were more general and did not focus 
390 specifically on PA. Until now, almost no studies examining potential correlates of sedentary

391 behaviors used questions specifically related to sedentary behaviors, mainly because this type of

392 research is still in its infancy, and little is known about its potential correlates. Also theoretical

393 frameworks should be fine-tuned and tested empirically: the socio-ecological framework of PA

394 (Sallis et al, 2008) has been adapted for sedentary behavior (Owen et al, 2011) and is now being

395 increasingly used in sedentary behavior research, but it seems that more thorough adaptation and

396 the inclusion of novel sedentary-specific correlates is still needed. In that context, Chastin and

397 colleagues (2016) recently introduced the Systems Of Sedentary behaviors (SOS) framework, an

398 adaptation of the framework of Owen et al (2011). The SOS framework has been developed

399 based on literature review and expert meetings, and is a transdisciplinary model taking into

400 account six clusters of potential determinants of sedentary behavior. Future research should

401 empirically examine the theoretical correlates of the SOS framework in order to find out whether

402 including these factors can increase the explained variance.

403

404 When examining the results in more detail, it can be concluded that the physical environmental

405 perceptions (residential density) were important to explain changes in active transportation. Also

406 in previous (cross-sectional) studies in adults and older adults, transportation PA was more

407 frequently related to the physical environment than recreational PA (Van Cauwenberg et al,

408 2011; Van Holle et al, 2012). Walkability characteristics like residential density and land use mix

409 access have been consistently associated with active (and passive) transportation in adults (Van

410 Holle et al, 2012), but evidence in older adults is less consistent (Van Cauwenberg et al, 2011;

411 Bauman et al, 2012). The present study adds evidence for the importance of the built

412 environment in recently retired adults and confirms the assumption that living in a high walkable 
413 neighborhood can be beneficial to increase active transportation. So, as emphasized in previous

414 studies in adults (Heath et al, 2006; Bauman et al, 2012; Sallis et al, 2016) health interventions

415 and policy makers should pay attention to optimizing the walkability of neighborhoods for active

416 transportation, and to make people who live in less walkable environments aware of the

417 possibilities that do exist in their neighborhood (e.g. recreational facilities). In that way, not only

418 adults, but also the specific group of recently retired adults can potentially be reached.

419

420 Self-efficacy (i.e. confidence in the ability to be active without a sport partner, when not having a

421 lot of time, when not feeling well and when the weather is not good) was the only factor that

422 predicted a positive change in leisure-time PA in the total sample. Previous studies have shown

423 that self-efficacy is amongst the most important determinants of leisure-time PA in (older) adults

424 (Caudroit, Stephan \& Le Scanff, 2011; Koeneman et al, 2011; Bauman et al, 2012; Van Stralen

425 et al, 2009). Nonetheless, it was somewhat surprising that no other psychological or social

426 factors were related to change in leisure-time PA since results of previous qualitative studies in

427 recently retired adults identified several specific intra- and interpersonal correlates of leisure-

428 time PA, like social support, perceived health benefits and financial constraints (Barnett, Guell \&

429 Ogilvie, 2012; McDonald et al, 2015; Kosteli, Williams \& Cumming, 2016; Van Dyck et al, in

430 press). These variables were also assessed in our study, but were not related to the outcome

431 measures. The current quantitative study could not confirm these previous qualitative results. The

432 importance of self-efficacy confirms that future interventions should be multi-dimensional and

433 combine an individual with an environmental focus, in order to increase different types of PA in

434 recently retired adults (Sallis, Owen \& Fisher, 2008).

435 
436 Unexpected results were found regarding the correlates of change in screen time: adults with

437 positive perceptions of old age and those who perceived higher street connectivity showed an

438 increase in screen time. These findings are opposite to what one would expect from the socio-

439 ecological framework for sedentary behavior (Owen et al, 2011). In this framework it is

440 suggested that perceiving high street connectivity and having a positive psychosocial profile

441 would be related to less sedentary time. This may confirm the assumption that correlates that

442 focus on PA seem not really suitable to be linked to sedentary behaviors. Previous literature on

443 the multidimensional correlates of sedentary behaviors in (older) adults is very limited, but the

444 available evidence also showed inconsistent associations of street connectivity and other aspects

445 of the physical environment with sedentary behaviors: some studies found negative associations

446 (Sugiyama et al, 2007; King et al, 2010), while other studies found no or positive associations

447 (Kozo et al, 2012; Teychenne, Ball \& Salmon, 2012; Chastin et al, 2015). Furthermore, it might

448 be that other factors like the home environment (e.g. number of screens in the home, having a

449 TV in the bedroom; Jones et al, 2010), or automatic processes and habit strength are more

450 strongly related to changes in screen time than the currently included variables (Conroy et al,

451 2013).

452

453 Some moderating effects of educational level and gender were identified; however one should

454 keep in mind that most of these results were only marginally significant: higher levels of

455 modelling from (grand)children only predicted an increase in active transport in high-educated

456 adults, while only in low-educated adults, a more positive perception of retirement (i.e.

457 perceiving retirement as a start for a more active lifestyle) predicted an increase in leisure-time

458 PA. The two other moderating effects were in the unexpected direction (i.e. in men and high- 
459 educated adults, higher modelling from friends predicted an increase in car use). Because only

460 four of the forty examined moderating effects were significant, one can presume that generic

461 interventions focusing on men and women, as well as low- and high-educated retired adults have

462 the potential to be effective. Emphasizing specific aspects in low- or high-educated adults, like a

463 focus on modelling from grand(children) in high-educated adults or on obtaining a positive

464 perception of retirement in low-educated adults, could increase the effectiveness of such

465 interventions.

466

467 Strengths of this study firstly include its longitudinal design. Second, we focused specifically on adults who are at the start of retirement, which is an important but currently understudied group

469 in health research. Third, a broad range of PA and sedentary behaviors were examined while 470 previous studies mainly focused on either leisure-time PA or TV viewing time, and not on active 471 transportation or car use. However, some limitations should be acknowledged. First, a relatively 472 small sample of recently retired adults participated in the study, limiting the power of our 473 analyses, the generalizability of our findings, and possibly inducing selection bias. Second, only

474 self-reported PA and sedentary behaviors were included. Third, most included predictors 475 primarily focused on PA and not specifically on sedentary behaviors.

477 Based on the current findings and limitations, we can formulate some suggestions for future 478 research. First, it is recommended to combine the use of questionnaires with objective 479 assessments of sedentary time. Second, potential sedentary-specific factors (e.g. habit strength of 480 sedentary behaviors, home environmental factors) should be included to further unravel the 481 determinants of changes in car use, screen time and other sedentary behaviors. 


\section{Conclusions}

484

485

In conclusion, this study showed that walkability characteristics (perceived residential density)

486 and self-efficacy at the start of retirement can predict longitudinal changes in active

487 488

transportation and leisure-time PA. Few moderating effects of gender and educational level were found, so health interventions at the start of retirement, focusing on self-efficacy and specific walkability characteristics, could be effective to increase PA in recently retired adults. No firm conclusions can be drawn on the importance of the examined predictors to explain change in car use and screen time because the explained variances of these regression models were small. Possibly other factors like the home environment, or automatic processes and habit strength are more important to explain sedentary behaviors.

\section{References}

Barnett I, Guell C, Ogilvie D. 2012. The experience of physical activity and the transition to retirement: a systematic review and integrative synthesis of qualitative and quantitative evidence. International Journal of Behavioral Nutrition and Physical Activity 9: 97. doi: 10.1186/14795868-9-97.

Barnett I, van Sluijs E, Ogilvie D, Wareham NJ. 2014. Changes in household, transport and recreational physical activity and television viewing time across the transition to retirement: 
504 longitudinal evidence from the EPIC Norfolk cohort. Journal of Epidemiology and Community 505 Health 68: 747-753. doi: 10.1136/jech-2013-203225.

506

507 Barnett I, van Sluijs EMF, Ogilvie D. 2012. Physical activity and transitioning to retirement: a 508 systematic review. American Journal of Preventive Medicine 43: 329-336. doi:

509 10.1016/j.amepre.2012.05.026.

510

511 Bauman AE, Reis RS, Sallis JF, Wells JC, Loos RJF, Martin BW, for the Lancet Physical 512 Activity Series Working Group. 2012. Correlates of physical activity: why are some people 513 physically active and others not? Lancet 380: 258-271. doi: 10.1016/S0140-6736(12)60735-1.

514

515 Bland JM, Altman DG. 1994. Regression towards the mean. British Medical Journal 308: 1499. 516

517 Caudroit J, Stephan Y, Le Scanff C. 2011. Social cognitive determinants of physical activity 518 among retired older individuals: an application of the health action process approach. British 519 Journal of Health Psychology 16: 404-417. doi: 10.1348/135910710X518324.

520

521 Chastin SFM, Buck C, Freiberger E, Murphy M, Brug J, Cardon G, O’Donoghue G, Pigeot I, 522 Oppert JM, DEDIPAC consortium. 2015. Systematic literature review of determinants of 523 sedentary behaviour in older adults: a DEDIPAC study. International Journal of Behavioral 524 Nutrition and Physical Activity 12: 127. doi: 10.1186/s12966-015-0292-3. 525 
526 Chastin S, De Craemer M, Lien N, Bernaards C, Buck C, Oppert JM, Nazare JA, Lakerveld J,

527 O’Donoghue G, Holdsworth M, Owen N, Brug J, Cardon G, DEDIPAC consortium, expert

528 working group and consensus panel. 2016. The SOS-framework (Systems of Sedentary

529 behaviours): an international transdisciplinary consensus framework for the study of

530 determinants, research priorities and policy on sedentary behaviour across the life course: a

531 DEDIPAC-study. International Journal of Behavioral Nutrition and Physical Activity 13: 83.

532 doi: 10.1186/s12966-016-0409-3

533

534 Chung S, Domino ME, Stearns SC, Popkin BM. 2009. Retirement and physical activity: analyses

535 by occupation and wealth. American Journal of Preventive Medicine 36: 422-428. doi:

536 10.1016/j.amepre.2009.01.026.

537

538 Cohen J, Cohen P. 1985. Applied multiple regression/correlation for the behavioral sciences. $2^{\text {nd }}$ 539 ed. Hillsdale: Erlbaum.

541 Conroy DE, Maher JP, Elavsky S, Hyde AL, Doerksen SE. 2013. Sedentary behavior as a daily 542 process regulated by habits and intentions. Health Psychology 32: 1149-1157. doi:

$543 \quad 10.1037 / \mathrm{a} 0031629$.

545 Craig CL, Marshall AL, Sjöström M, Bauman AE, Booth ML, Ainsworth BE, Pratt M, Ekelund

546 U, Yngve A, Sallis JF, Oja P. 2003. International Physical Activity Questionnaire: 12-country

547 reliability and validity. Medicine \& Science in Sports \& Exercise 35: 1381-1395. 
549 De Bourdeaudhuij I, Sallis JF. 2002. Relative contribution of psychological determinants to the 550 prediction of physical activity in three population based samples. Preventive Medicine 34: 279551288.

552

553 De Bourdeaudhuij I, Sallis JF, Saelens BE. 2003. Environmental correlates of physical activity in 554 a sample of Belgian adults. American Journal of Health Promotion 18: 83-92.

555

556 De Bourdeaudhuij I, Lefevre J, Deforche B, Wijndaele K, Matton L, Philippaerts R. 2005.

557 Physical activity and psychosocial correlates in normal and overweight 11 to 19 year olds. 558 Obesity Reviews 13: 1097-1105.

559

560

De Cocker K, De Bourdeaudhuij I, Cardon G, Vandelanotte C. The effectiveness of a web-based 561 computer-tailored intervention on workplace sitting: a randomized controlled trial. 2016. Journal 562 of Medical Internet Research 18: e96. doi: 10.2196/jmir.5266

563

564

Deforche B, De Bourdeaudhuij I, Tanghe A, Hills AP, De Bode P. 2004. Changes in physical 565 activity and psychosocial determinants of physical activity in children and adolescents treated for 566 obesity. Patient Education \& Counseling 55: 407-415.

567

568 Federal Pensions Service Belgium. Available at: http://www.onprvp.fgov.be Accessed on May 569182016.

570 
571 Heath G, Brownson R, Kruger J, Miles R, Powell KE, Ramsey LT, the Task Force on

572 Community Preventive Services. 2006. The effectiveness of urban design and land use and

573 transport policies to increase physical activity: a systematic review. Journal of Physical Activity

574 \& Health 3: S55-S76.

575

576 Jones KE, Otten JJ, Johnson RK, Harvey-Bering JR. 2010. Removing the bedroom television set; 577 a possible method for decreasing television viewing time in overweight and obese adults. Behav 578 Modif 34: 290. doi: 10.1177/0145445510370994.

579

Jonsson H, Josephsson S, Kielhofner G. 2001. Narratives and experience in an occupational 581 transition: a longitudinal study of the retirement process. American Journal of Occupational 582 Therapy 55: 424-432.

583

584 Kim JE, Moen P. 2002. Retirement transitions, gender, and psychological well-being: a life585 course, ecological model. The Journals of Gerontology Series B: Psychological Sciences and 586 Social Sciences 57: 212-222.

587

588 King AC, Goldberg JH, Salmon J, Owen N, Dunstan D, Weber D, Doyle C, Robinson TN. 2010. 589 Identifying subgroups of US adults at risk for prolonged television viewing to inform program 590 development. American Journal of Preventive Medicine 38: 17-26. doi:

591 10.1016/j.amepre.2009.08.032. 
593 King DE, Mainous AG 3rd, Geesey ME. 2007. Turning back the clock: adopting a healthy

594 lifestyle in middle age. The American Journal of Medicine 120: 598-603.

595

596 Knoops KT, de Groot LC, Kromhout D, Perrin AE, Moreiras-Varela O, Menotti A, van Staveren 597 WA. 2004. Mediterranean diet, lifestyle factors, and 10-year mortality in elderly European men 598 and women: the HALE project. Journal of the American Medical Association 292: 1433-1439. 599

600

Koeneman MA, Verheijden MW, Chinapaw MJM, Hopman-Rock M. 2011. Determinants of 601 physical activity and exercise in healthy older adults: a systematic reviews. International Journal 602 of Behavioral Nutrition and Physical Activity 8: 142. doi: 10.1186/1479-5868-8-142.

603

604

Kosteli M, Williams SE, Cumming J. 2016. Investigating the psychosocial determinants of 605 physical activity in older adults: a qualitative approach. Psychology \& Health 31: 730-749. doi: 606 10.1080/08870446.2016.1143943.

607

608

Kozo J, Sallis JF, Conway TL, Kerr J, Cain K, Saelens BE, Frank LD, Owen N. 2012. Sedentary 609 behaviors of adults in relation to neighborhood walkability and income. Health Psychology 31: 610 704-713. doi: 10.1037/a0027874.

611

612 Lahti J, Laaksonen M, Lahelma E, Rahkonen O. 2011. Changes in leisure-time physical activity 613 after transition to retirement: a follow-up study. International Journal of Behavioral Nutrition 614 and Physical Activity 8: 36. doi: 10.1186/1479-5868-8-36. 
616 Lang IA, Rie NE, Wallace RB, Guralnik JM, Melzer D. 2007. Smoking cessation and transition

617 into retirement: analyses from the English Longitudinal Study of Ageing. Age and Ageing 36, $618 \quad 638-643$.

619

620 Marcus BH, Selby VC, Niaura RS, Rossi JS. 1992. Self-efficacy and the stages of exercise 621 behavior change. Research Quarterly for Exercise and Sport 63: 60-66.

622

623 McDonald S, O'Brien N, White M, Sniehotta FF. 2015. Changes in physical activity during the 624 retirement transition: a theory-based, qualitative interview study. International Journal of 625 Behavioral Nutrition and Physical Activity 12: 25. doi: 10.1186/s12966-015-0186-4.

626

627 Mein GK, Shipley MJ, Hillsdon M, Ellison GT, Marmot MG. 2005. Work, retirement and 628 physical activity: cross-sectional analyses from the Whitehall II study. European Journal of 629 Public Health 15: 317-322.

630

631 Organization for Economic Cooperation and Development. 2006. Study projects growing 632 pressure on public health spending over and above effects of ageing society. Paris, France. 633 Organization for Economic Cooperation and Development. Available at: $\underline{\text { http://www.oecd.org }}$ 634 Accessed April 202016.

635

636 Owen N, Sugiyama T, Eakin E, Gardiner PA, Tremblay MS, Sallis JF. 2011. Adults' sedentary 637 behavior: determinants and interventions. Am J Prev Med 41: 189-196. doi:

638 10.1016/j.amepre.2011.05.013. 
639

640 Saelens BE, Sallis JF, Frank LD. 2003. Environmental correlates of walking and cycling:

641 findings from transportation, urban design, and planning literatures. Annals of Behavioral

642 Medicine 25: 80-91.

643

644 Sallis JF, Cerin E, Conway TL, Adams MA, Frank LD, Pratt M, Salvo D, Schipperijn J, Smith

645 G, Cain KL, Davey R, Kerr J, Lai PC, Mitas J, Reis R, Sarmiento OL, Schofield G, Troelsen J, 646 Van Dyck D, De Bourdeaudhuij I, Owen N. 2016. Physical activity in relation to urban

647 environments in 14 cities worldwide: a cross-sectional study. Lancet 387: 2207-2217. doi:

648 10.1016/S0140-6736(15)01284-2.

649

650 Sallis JF, Grossman RM, Pinski RB, Patterson TL, Nader PR. 1987. The development of scales 651 to measure social support for diet and exercise behaviors. Preventive Medicine 16: 825-836.

652

653 Sallis JF, Owen N, Fisher EB. 2008. Ecological models of health behavior. In Glanz K, Rimer

654 BK, Viswanath K, eds. Health behavior and health education: Theory, research and practice.

655 San Francisco, CA: Jossey-Bass, 465-486.

656

657 Salmon J, Owen N, Crawford D, Bauman A, Sallis JF. 2003. Physical activity and sedentary

658 behavior: a population-based study of barriers, enjoyment and preference. Health Psychology 22:

$659 \quad 178-188$.

660 
661 Sampson RJ, Raudenbush SW, Earls F. 1997. Neighborhoods and violent crime: a multilevel 662 study of collective efficacy. Science 277: 918-924.

663

664 Slingerland AS, van Lenthe FJ, Jukema JW, Kamphuis CBM, Looman C, Giskes K, Huisman M, 665 Narayan KM, Mackenbach JP, Brug J. 2007. Aging, retirement, and changes in physical activity: 666 prospective cohort findings from the GLOBE Study. American Journal of Epidemiology 165: 667 1356-1363.

668

669 Sprod J, Ferrar K, Olds T, Maher C. 2015. Changes in sedentary behaviours across the retirement 670 transition: a systematic review. Age and Ageing 44, 918-925. doi: 10.1093/ageing/afv140.

671

672 Sugiyama T, Salmon J, Dunstan DW, Bauman AE, Owen N. 2007. Neighborhood walkability 673 and TV viewing time among Australian adults. American Journal of Preventive Medicine 33: 674 444-449.

675

676 Tabachnik BG, Fidell LS. 2007. Using multivariate statistics. $5^{\text {th }}$ ed. Boston: Allyn and Bacon: 677 p. 140.

678

679 Teychenne M, Ball K, Salmon J. 2012. Correlates of socio-economic inqualities in women’s 680 television viewing: a study of intrapersonal, social and environmental mediator. International 681 Journal of Behavioral Nutrition and Physical Activity 9: 3. doi: 10.1186/1479-5868-9-3. 
683 Touvier M, Bertrais S, Charreire H, Vergnaud AC, Hercberg S, Oppert JM. 2010. Changes in

684 leisure-time physical activity and sedentary behaviour at retirement: a prospective study in 685 middle-aged French subjects. International Journal of Behavioral Nutrition and Physical 686 Activity 7: 1-14. doi: 10.1186/1479-5868-7-14.

687

688 Van Cauwenberg J, De Bourdeaudhuij I, De Meester F, Van Dyck D, Salmon J, Clarys P, 689 Deforche B. 2011. Relationship between the physical environment and physical activity in older 690 adults: a systematic review. Health \& Place 17: 458-469. doi:

691 10.1016/j.healthplace.2010.11.010.

692

693 Van Dyck D, Mertens L, Cardon G, De Cocker K, De Bourdeaudhuij I. Opinions towards 694 physical activity, sedentary behavior and interventions to stimulate active living during early 695 retirement: a qualitative study in recently retired adults. Journal of Aging and Physical Activity, 696 in press.

697

698 Van Holle V, Deforche B, Van Cauwenberg J, Goubert L, Maes L, Van de Weghe N, De 699 Bourdeaudhuij I. 2012. Relationship between the physical environment and different domains of 700 physical activity in European adults: a systematic review. BMC Public Health 12: 807. doi:

$701 \quad 10.1186 / 1471-2458-12-807$.

702

703 Van Holle V, Van Cauwenberg J, Deforche B, Van de Weghe N, De Bourdeaudhuij I, Van Dyck 704 D. 2015. Do psychosocial factors moderate the association between objective neighborhood 
705 walkability and older adults' physical activity? Health \& Place 34: 118-125. doi:

$706 \quad 10.1016 /$ j.healthplace.2015.05.004

707

708 Van Holle V, Van Cauwenberg J, Gheysen F, Van Dyck D, Deforche B, Van de Weghe N, De

709 Bourdeaudhuij I. 2016. The association between Belgian older adults' physical functioning and

710 physical activity: what is the moderating role of the physical environment? PLOS ONE 11(2):

711 e0148398. doi: 10.1371/journal.pone.0148398.

712

713 Van Stralen MM, De Vries H, Mudde AN, Bolman C, Lechner L. 2009. Determinants of

714 initiation and maintenance of physical activity among older adults: a literature review. Health

715 Psychol Rev 3: 147-207. doi: 10.1080/17437190903229462.

716

717 World Health Organization. 2014. 10 Facts on ageing and the life course. Geneva, Switzerland. 


\section{Table $\mathbf{1}$ (on next page)}

Baseline descriptive characteristics of the study sample $(n=180)$

${ }^{a}$ positively scored on a five-point scale ${ }^{b}$ positively scored on a three-point scale ${ }^{c}$ positively scored on a seven-point scale ${ }^{d}$ positively scored on a four-point scale 
1 Table 1: Baseline descriptive characteristics of the study sample $(n=180)$

\begin{tabular}{|c|c|}
\hline Variable & \\
\hline \multicolumn{2}{|l|}{ Socio-demographic covariates } \\
\hline \multicolumn{2}{|l|}{ Gender (\%) } \\
\hline Men & 48.6 \\
\hline Women & 51.4 \\
\hline Age (mean (SD)) & $62.5(2.1)$ \\
\hline \multicolumn{2}{|l|}{ Educational level (\%) } \\
\hline High educational level & 54.5 \\
\hline Low educational level & 45.5 \\
\hline Body Mass index (mean (SD)) & $25.4(3.9)$ \\
\hline \multicolumn{2}{|l|}{ Predictors (mean (SD)) } \\
\hline \multicolumn{2}{|l|}{ Psychological factors } \\
\hline Perceived benefits ${ }^{a}$ & $3.6(0.6)$ \\
\hline Perceived barriers a & $4.1(0.7)$ \\
\hline Self-efficacy ${ }^{b}$ & $2.1(0.54)$ \\
\hline \multicolumn{2}{|l|}{ Perceptions of retirement ${ }^{a}$} \\
\hline Retirement = slowing down & $2.5(1.1)$ \\
\hline Retirement $=$ more active life & $3.2(1.1)$ \\
\hline Perception of old age ${ }^{\text {a }}$ & $3.5(0.5)$ \\
\hline \multicolumn{2}{|l|}{ Social factors } \\
\hline Modelling from partner ${ }^{c}$ & $4.5(2.2)$ \\
\hline Modelling from friends ${ }^{c}$ & $4.2(1.9)$ \\
\hline Modelling from (grand)children ${ }^{c}$ & $5.0(1.5)$ \\
\hline Social support ${ }^{a}$ & $3.6(1.0)$ \\
\hline Neighborhood social cohesion ${ }^{a}$ & $3.6(0.7)$ \\
\hline \multicolumn{2}{|l|}{ Physical environmental factors } \\
\hline Residential density ${ }^{b}$ & $192.6(77.8)$ \\
\hline Land use mix diversity $^{a}$ & $3.0(0.8)$ \\
\hline Land use mix access $^{d}$ & $3.2(0.8)$ \\
\hline Street network connectivity ${ }^{d}$ & $2.9(0.5)$ \\
\hline $\begin{array}{l}\text { Infrastructure and safety for } \\
\text { walking and cycling }{ }^{d}\end{array}$ & $2.5(0.5)$ \\
\hline Traffic safety ${ }^{d}$ & $2.5(0.6)$ \\
\hline Crime safety ${ }^{d}$ & $3.0(0.6)$ \\
\hline Aesthetics ${ }^{d}$ & $2.5(0.6)$ \\
\hline
\end{tabular}

Dependent variables (mean (SD))

Physical activity ( $\mathrm{min} /$ week)

Active transportation

$240.8(253.0)$

Leisure-time physical activity

$312.4(359.2)$

Sedentary behaviors ( $\mathrm{min} /$ week)

Screen time

$1425.4(777.2)$

Car use

2 a positively scored on a five-point scale

$3{ }^{b}$ positively scored on a three-point scale

4 c positively scored on a seven-point scale

5 d positively scored on a four-point scale 


\section{Table 2 (on next page)}

Multiple moderated hierarchic regression analyses: associations with changes in PA and moderating effects of educational level and gender

$\mathrm{PA}=$ physical activity, $\mathrm{Cl}=$ confidence interval, $\mathrm{Adj}=$ adjusted $*$ Block $3 \mathrm{~A}:$ regression model with educational level as a moderator ${ }^{*}$ Block $3 \mathrm{~B}$ : regression model with gender as a moderator 
Table 2: Multiple moderated hierarchic regression analyses: associations with changes in PA and moderating effects of educational level and

2 gender

\begin{tabular}{|c|c|c|c|c|c|}
\hline Dependent variable & Predictors & Adj $R^{2}$ & $\beta$ value & $95 \% \mathrm{Cl}$ & $\mathrm{p}$-value \\
\hline Change in active & Block 1 (sociodemographic covariates) & 0.009 & & & \\
\hline \multirow[t]{30}{*}{ transportation } & Block 2 & 0.188 & & & \\
\hline & Self-efficacy & & 0.01 & $-0.31,0.37$ & 0.88 \\
\hline & Retirement $=$ slowing down & & 0.10 & $-0.08,0.25$ & 0.30 \\
\hline & Modelling from (grand)children & & 0.12 & $-0.04,0.19$ & 0.22 \\
\hline & Neighborhood social cohesion & & -0.05 & $-0.35,0.20$ & 0.60 \\
\hline & Residential density & & 0.41 & $0.002,0.008$ & $<0.001$ \\
\hline & Land use mix access & & 0.07 & $-0.18,0.34$ & 0.55 \\
\hline & Street network connectivity & & -0.12 & $-0.64,0.19$ & 0.28 \\
\hline & Infrastructure/safety for walking and cycling & & 0.11 & $-0.27,0.70$ & 0.39 \\
\hline & Aesthetics & & -0.18 & $-0.58,0.03$ & 0.08 \\
\hline & Block $3 A^{*}$ & 0.180 & & & \\
\hline & Educational level $\times$ self-efficacy & & 0.21 & $-0.53,0.85$ & 0.64 \\
\hline & $\times$ retirement $=$ slowing down & & -0.03 & $-0.38,0.34$ & 0.91 \\
\hline & $\times$ modelling from (grand)children & & 0.66 & $-0.04,0.50$ & 0.09 \\
\hline & $\times$ neighborhood social cohesion & & 0.39 & $-0.44,0.81$ & 0.56 \\
\hline & $\times$ residential density & & 0.02 & $-0.005,0.006$ & 0.94 \\
\hline & $x$ land use mix access & & 0.76 & $-0.16,1.03$ & 0.15 \\
\hline & x street network connectivity & & 0.36 & $-0.69,1.15$ & 0.62 \\
\hline & $\times$ infrastructure/safety for walking and cycling & & -0.22 & $-1.21,0.90$ & 0.77 \\
\hline & $\times$ aesthetics & & -0.02 & $-0.77,0.74$ & 0.97 \\
\hline & Block $3 B^{¥}$ & 0.152 & & & \\
\hline & Gender $\times$ self-efficacy & & -0.30 & $-0.96,0.47$ & 0.50 \\
\hline & $\times$ retirement $=$ slowing down & & 0.07 & $-0.35,0.43$ & 0.84 \\
\hline & $\times$ modelling from (grand)children & & 0.37 & $-0.13,0.38$ & 0.33 \\
\hline & $\times$ neighborhood social cohesion & & 0.23 & $-0.46,0.68$ & 0.70 \\
\hline & $\times$ residential density & & -0.47 & $-0.01,0.002$ & 0.22 \\
\hline & $x$ land use mix access & & 0.31 & $-0.44,0.77$ & 0.59 \\
\hline & x street network connectivity & & 0.67 & $-0.45,1.28$ & 0.34 \\
\hline & x infrastructure/safety for walking and cycling & & -0.72 & $-1.57,0.54$ & 0.34 \\
\hline & $x$ aesthetics & & -0.41 & $-0.96,0.39$ & 0.41 \\
\hline
\end{tabular}




\begin{tabular}{|c|c|c|c|c|c|}
\hline \multirow[t]{22}{*}{ Change in leisure-time PA } & Block 1 (sociodemographic covariates) & 0.065 & & & \\
\hline & Block 2 & 0.199 & & & \\
\hline & Perceived benefits & & 0.03 & $-0.25,0.35$ & 0.74 \\
\hline & Self-efficacy & & 0.32 & $0.26,0.94$ & 0.001 \\
\hline & Retirement $=$ more active life & & 0.08 & $-0.09,0.24$ & 0.37 \\
\hline & Modelling from partner & & 0.05 & $-0.05,0.10$ & 0.55 \\
\hline & Land use mix access & & 0.06 & $-0.14,0.28$ & 0.51 \\
\hline & Traffic safety & & 0.14 & $-0.04,0.45$ & 0.10 \\
\hline & Block $3 A^{*}$ & 0.204 & & & \\
\hline & Educational level $\times$ perceived benefits & & 0.30 & $-0.48,0.79$ & 0.63 \\
\hline & $\times$ self-efficacy & & 0.26 & $-0.46,0.88$ & 0.54 \\
\hline & $\times$ retirement $=$ more active life & & -0.68 & $-0.69,-0.01$ & 0.045 \\
\hline & $\times$ modelling from partner & & -0.17 & $-0.21,0.10$ & 0.39 \\
\hline & $\times$ land use mix access & & 0.18 & $-0.34,0.54$ & 0.65 \\
\hline & $x$ traffic safety & & -0.22 & $-0.68,0.38$ & 0.57 \\
\hline & Block $3 B^{¥}$ & 0.168 & & & \\
\hline & Gender $\times$ perceived benefits & & 0.35 & $-0.52,0.89$ & 0.61 \\
\hline & × self-efficacy & & -0.17 & $-0.84,0.55$ & 0.68 \\
\hline & $\times$ retirement $=$ more active life & & -0.05 & $-0.38,0.32$ & 0.88 \\
\hline & $\times$ modelling from partner & & 0.07 & $-0.13,0.18$ & 0.76 \\
\hline & $\times$ land use mix access & & -0.34 & $-0.64,0.26$ & 0.41 \\
\hline & $x$ traffic safety & & -0.26 & $-0.71,0.34$ & 0.49 \\
\hline
\end{tabular}

$3 \quad \mathrm{PA}=$ physical activity, $\mathrm{Cl}=$ confidence interval, $\mathrm{Adj}=$ adjusted

* Block 3A: regression model with educational level as a moderator

${ }^{\sharp}$ Block 3B: regression model with gender as a moderator 


\section{Table 3(on next page)}

Multiple moderated hierarchic regression analyses: associations with changes in sedentary behaviors and moderating effects of gender and educational level

$\mathrm{PA}=$ physical activity, $\mathrm{Cl}=$ confidence interval $*$ Block $3 \mathrm{~A}$ : regression model with educational level as a moderator ${ }^{\sharp}$ Block $3 \mathrm{~B}$ : regression model with gender as a moderator 
Table 3: Multiple moderated hierarchic regression analyses: associations with changes in sedentary behaviors and moderating effects of gender and educational level

\begin{tabular}{|c|c|c|c|c|c|}
\hline Dependent variable & Predictors & Adj $R^{2}$ & $\beta$ value & $95 \% \mathrm{Cl}$ & $p$-value \\
\hline \multirow[t]{10}{*}{ Change in screen time } & Block 1 (sociodemographic covariates) & 0.052 & & & \\
\hline & Block 2 & 0.116 & & & \\
\hline & Perception of old age & & 0.16 & $0.02,0.61$ & 0.04 \\
\hline & Street network connectivity & & -0.25 & $-0.69,-0.17$ & 0.001 \\
\hline & Block $3 A^{*}$ & 0.105 & & & \\
\hline & Educational level $\times$ perception of old age & & 0.02 & $-0.59,0.62$ & 0.97 \\
\hline & $\times$ street network connectivity & & -0.04 & $-0.54,0.50$ & 0.93 \\
\hline & Block $3 B^{¥}$ & 0.105 & & & \\
\hline & Gender $\times$ perception of old age & & -0.07 & $-0.65,0.57$ & 0.91 \\
\hline & $\times$ street network connectivity & & 0.11 & $-0.46,0.60$ & 0.80 \\
\hline \multirow[t]{13}{*}{ Change in car use } & Block 1 (sociodemographic covariates) & -0.015 & & & \\
\hline & Block 2 & 0.058 & & & \\
\hline & Modelling from friends & & 0.21 & $-0.01,0.24$ & 0.06 \\
\hline & Residential density & & -0.14 & $-0.005,0.001$ & 0.26 \\
\hline & Land use mix access & & -0.20 & $-0.54,0.04$ & 0.09 \\
\hline & Block $3 A^{*}$ & 0.084 & & & \\
\hline & Educational level $\times$ modelling from friends & & 0.63 & $-0.01,0.51$ & 0.06 \\
\hline & × Residential density & & -0.20 & $-0.01,0.004$ & 0.54 \\
\hline & $\times$ Land use mix access & & -0.67 & $-1.11,0.27$ & 0.23 \\
\hline & Block 3B & 0.080 & & & \\
\hline & Gender $\times$ modelling from friends & & -0.54 & $-0.47,0.02$ & 0.08 \\
\hline & $\times$ Residential density & & 0.05 & $-0.006,0.007$ & 0.89 \\
\hline & $\times$ Land use mix access & & 0.57 & $-0.26,0.95$ & 0.26 \\
\hline
\end{tabular}

$4 \quad \mathrm{PA}=$ physical activity, $\mathrm{Cl}=$ confidence interval

* Block 3A: regression model with educational level as a moderator

${ }^{\sharp}$ Block 3B: regression model with gender as a moderator 